\title{
Assessment of Availability of Human Resource and Services for Newborn Care in Primary Health Care Facilities in Jos North Local Government Area of Plateau State, Nigeria
}

Toma BO, ${ }^{1}$ Ofakunrin AOD, ${ }^{1}$ Diala UM, ${ }^{1}$ Kanhu ${ }^{2},{ }^{2}$ Baba F, ${ }^{3}$ Shwe DD. ${ }^{1}$

1. Department of Paediatrics, College of Health Sciences, University of Jos, Jos, Plateau State, Nigeria

2. Department of Paediatrics, Jos University Teaching Hospital, Jos, Plateau Sate, Nigeria

3. Federal Medical Centre, Yola, Nigeria

Corresponding Author: Bose $\mathrm{O}$. Toma,

E-mail: gabosetoma@,gmail.com;

\begin{abstract}
Background: Majority of neonatal deaths occur in low and middle income countries. Availability of qualified human resource along with maternal and child health services are essential to curb these deaths. The study objective was to determine the availability of human resource and services for newborn care in Primary Health Care facilities in Jos North Local Government Area.
\end{abstract}

Methods: This was a descriptive cross-sectional study conducted in Primary Health Care facilities offering immediate newborn care. A stratified sampling technique was used to select 67 and 60 healthcare workers in 30 public and 30 private facilities respectively. A structured questionnaire was used to collect data and SPSS version 23 used for data analysis.

Results: Majority, 85(66.9\%) of the healthcare workers were Community Health Extension Workers. There were 16(12.6\%) midwives and 1(0.8\%) medical doctor. In-service training on newborn care had been received by $69(54.3 \%)$ respondents, while $22(17.3 \%)$ respondents had received training on essential newborn care. Only twenty (33.3\%) facilities discharge mother and newborn 24 hours after normal delivery. Post natal services provided included early initiation of breast feeding by 116(91.3\%) respondents. Preventive services included chlorhexidine cord care given by $86(67.7 \%)$ respondents while $27(21.3 \%$ ) and $26(20.5 \%)$ gave erythromycin/ tetracycline eye prophylaxis and vitamin k1 respectively.

Conclusion: Community Health Extension Workers were the major human resource for immediate newborn care; further research to determine their knowledge and skills are needed. The preventive neonatal services were few. More preventive care and 24 hour postnatal care are advocated as strategies to improve newborn outcome.

\section{Key words}

Human resource; skilled birth attendant; neonatal services; newborn care; Jos Nigeria; 


\section{Introduction}

Neonatal mortality is high accounting for $47 \%$ of under-five deaths globally. ${ }^{1}$ Worldwide, in 2019, there were 2.4 million neonatal deaths with majority (98\%) occurring in Low and Middle Income Countries (LMICs). ${ }^{1,2}$ Nigeria contributed 270,000 neonatal deaths that year which was the highest in Africa and the second highest in the world. ${ }^{3}$ A third of neonatal deaths occur within the first day after birth, and close to three quarters occur within the first week of life. ${ }^{1}$ More than $80 \%$ of neonatal deaths are the result of causes that could have been prevented with basic good quality health care and include complications of premature birth, birth asphyxia and infections. ${ }^{4}$

Essential newborn care (ENC) is a comprehensive strategy that has been shown to reduce neonatal morbidity and mortality. ${ }^{5,6}$ Its components include clean delivery and clean cord care, thermal protection, early and exclusive breastfeeding, initiation of breathing, preventive care including eye care, immunization, management of newborn illness and care of the preterm and/or Low Birth Weight (LBW) newborn. Improving access to maternal and newborn health services is a necessary first step in bringing down rates of newborn mortality and the presence of qualified Human Resource (HR) during child birth plays an important role in improved birth outcomes and neonatal care. ${ }^{4,8,9}$

The Primary Health Care (PHC) level is the first of the three-tier health system in Nigeria and is usually the first point of contact between the patient and the health care delivery system. ${ }^{10}$ There are few published data in Nigeria on availability of human resource and services for newborn care at the PHC level of health care. The objective of this study therefore was to determine the availability of human resource and services for immediate newborn care in public and private $\mathrm{PHC}$ facilities in Jos North Local Government Area (LGA) of Plateau State, Nigeria.

\section{Methods}

\section{Study area}

This study was carried out in Jos North LGA, one of the 17 LGAs of Plateau State, north central Nigeria. It is a cosmopolitan, mainly urban area with a population of 572,700 projected from the 2006 national population census. ${ }^{11}$ The total registered live births (both facility and home) in Jos North LGA in the year preceding the study was 9,212. ${ }^{12}$ Healthcare is provided by Government (public) and private or nongovernmental institutions (including faithbased organizations) and is organized into primary, secondary and tertiary levels of care. ${ }^{13}$ There are 1,394 healthcare facilities in Plateau State out of which 1,335 are PHC facilities. ${ }^{14}$ Jos North LGA has 135 health facilities, the highest number in the State of which 72 (37 public and 35 private) are PHC facilities. ${ }^{14}$ There are 494 health care providers in all public and private PHCs in Jos North LGA, out of which 210 are involved in immediate newborn care.

\section{Study design and study population/ Inclusion criteria}

This was a cross-sectional descriptive study. All PHCs in Jos North LGA that conduct deliveries and provide immediate newborn care were enlisted. Seven of the public and five of the private PHCs do not take deliveries and thus were excluded from the study. This resulted in 30 public and 30 private PHC facilities. The study population comprised of Health Care Workers (HCWs) engaged in immediate newborn care service provision for at least six months.

\section{Sample size determination}

The sample size for the study was determined using the formula for determination of sample size when 
conducting a cross-sectional descriptive study: $n=\frac{z^{2} p q}{d^{2}}$ using a prevalence of $76.2 \%$ for availability of newborn care services in health facilities in Tanzania, assuming 5\% margin of error and 95\% confidence level. ${ }^{15,16}$ Because the source population was less than 10,000 , sample size correction was made, and $5 \%$ of the sample size added for non-response rate which gave a final minimum sample size of 126 HCWs. $^{15}$

Sampling techniqueA stratified sampling technique was employed in the study. Jos North LGA was purposively selected based on the fact that it has the largest number of health facilities; it is urban and hosts the State capital. The list of all registered PHC facilities in the LGA was obtained from the Plateau State Ministry of Health and the Plateau State Primary Health Care Board (PHCB). All the facilities offering immediate newborn care were then stratified by ownership into public and private.

\section{Selection of study Participants}

A list of all the PHC workers was obtained from the public and private $\mathrm{PHC}$ facilities. Those involved in delivery/ immediate newborn care were identified and served as the sampling frame for the private and public PHC facilities separately. There were $110 \mathrm{HCWs}$ from the public and 100 $\mathrm{HCWs}$ from private PHC facilities. A proportion to size method was used to select 67 and $60 \mathrm{HCWs}$ from public and private facilities respectively giving a total of $127 \mathrm{HCWs}$.

Thereafter, a computer program (Win Pepi version 11.39) was used to generate 67 and 60 random numbers each from the lists of public and private HCWs respectively to give the desired sample size of 127 . Where a HCW was persistently absent despite several visits, the next eligible $\mathrm{HCW}$ was recruited.

\section{Data collection}

The research tools were adapted from the World Health Organization (WHO)/American Academy of Pediatrics (AAP) Essential Newborn Care Course (ENCC) and also another study. ${ }^{17,18} \mathrm{~A}$ health facility check list was completed for each facility by interviewing the head of the facility, the health workers and inspection of records. Information obtained included availability of human resource, demographic data and provision of ENC services. Information on the services delivered at the facilities in relation to newborn care, such as number and details of births and referrals were obtained from the registers at the facilities. Also, a self-administered semi structured questionnaire based on ENCC requirements was administered to the HCWs. ${ }^{17}$ The research instruments were pre-tested. Six research assistants were recruited and trained for the study. The data was collected between $9^{\text {th }}$ September and $23^{\text {rd }}$ October 2019

\section{Data analysis}

Data analysis was carried out using Statistical Package for the Social Sciences version 23.0 software (IBM, SPSS Inc., Chicago, USA). Descriptive statistical analysis was carried out on qualitative variables and these were presented in frequency tables and expressed in frequencies and percentages. Quantitative variables like the age were summarized using mean and standard deviation (SD), while median and interquartile range (IQR) was used for the number of deliveries. The student's t test was used for comparison of mean age. Pearson's Chi square test was used for comparison of proportions of categorical variables like sex, qualification, available services between public and private facilities; and where appropriate, Fisher exact test was used. A p value of $<0.05$ was considered statistically significant. 


\section{Ethical considerations}

Ethical approval was obtained from the Health Research Ethics Committee of Jos University Teaching Hospital. Permission was obtained from the Plateau State Ministry of Health, PHCB and Jos North $\mathrm{PHC}$ unit. In addition, permission was also obtained from the heads of the health facilities. Verbal informed consent was sought and obtained from every respondent. Assurance of anonymity and confidentiality of all information supplied was given and ensured.

\section{Results}

Sixty PHC facilities were assessed, 30 $(50.0 \%)$ were public and the remaining 30 $(50.0 \%)$ private. Almost half $(13,43.3 \%)$ of the public facilities were headed by double qualified nurse/midwives, while the same number of private facilities were headed by medical doctors. Others include community health extension workers (CHEWs), $(\mathrm{p}<0.001)$ Table 1.

\section{Human resource}

There were $127 \mathrm{HCWs}, 67$ from public PHCs and 60 from private PHCs. Majority, $85(66.9 \%)$ of the HCWs were CHEWs and Junior Community Health Extension Workers (JCHEW s); $48(71.6 \%)$ public and $37(61.7 \%)$ private PHC workers. There were 16(12.6\%) midwives; $5(7.5 \%)$ public and $11(18.3 \%)$ private and $1(0.8 \%)$ medical doctor in a public PHC (Table 2). There was no significant difference in the qualification of the HCWs between the public and private PHCs $(p=0.28)$. Most of the HCWs were female $(116,91.0 \%)$, with no statistically significant difference between the public and private facilities $(\mathrm{p}=0.61)$. With regards to training, $69(54.3 \%)$ of the $\mathrm{HCW}$ s had some form of in-service newborn training with no significant difference between public and private facilities $(p=0.57)$. However, only $22(17.3 \%)$ had been trained on the ENCC.
Other characteristics are shown in Table 2.

\section{Services}

The annual deliveries in the year before the study ranged from 4-240 per facility. The total deliveries were 2,716 with 1,820 $(67.0 \%)$ of them being from the private facilities (Table 3). Only a few facilities had records on the number of still births, LBW and preterm babies. There were no records of number of babies with birth asphyxia in any of the facilities.

Most of the private facilities $(28,93.3 \%)$ offer 24 hour services in contrast to less than half $(14,46.7 \%)$ of the public facilities, $p<0.001$, (Table 4). Half (15, $50.0 \%)$ of the public PHCs discharge mothers and newborns within 2-6 hours after normal vaginal delivery, while only 20(33.3\% ) PHCs; 5(16.7\%) public and $15(50.0 \%)$ private, discharge mothers and newborns 24 hours after normal delivery, $\mathrm{p}=0.05$ (Table 4 ).

With regards to ENC services, 116(91.3\%) of the $127 \mathrm{HCWs}$; 61(91.0\%) from public and 55(91.7\%) from private PHCs initiate early breastfeeding within the first hour of life (Table 5). There was no significant difference between the public and private PHCs $(p=0.90)$. Similarly, 124(97.6\%) HCWs; 64(95.5\%) from public and all $60(100 \%)$ from private PHCs counsel the mothers after delivery on exclusive breast feeding $(E B F)$ for six months $(p=0.37)$. Cord care with chlorhexidine gel application to the umbilical cord after delivery was done by $86(67.7 \%) \mathrm{HCWs}$; $44(65.7 \%)$ public and $42(70.0 \%)$ private $(\mathrm{p}=0.60)$. However, in contrast, only $27(21.3 \%) \mathrm{HCWs} ; 11(16.4 \%)$ public and $16(26.7 \%)$ private applied erythromycin/tetracycline eye ointment to the eye of the newborn after delivery as eye prophylaxis $(\mathrm{p}=0.16)$. Also, only 26(20.5\%) HCWs; $12(17.9 \%)$ public and $14(23.3 \%)$ private gave intramuscular vitamin $\mathrm{K} 1$ routinely to the newborns ( $\mathrm{p}=$ $0.45)$ Table 5. 
Most of both the public and private PHCs $(50,83.0 \%)$ had immunization services (Table 4). Two PHCs, both private, had incubators. One (1.7\%) of the facilities had a visiting paediatrician who managed it and thus the service was provided, while in the second facility the incubator was not being used due to lack of a paediatrician. Similarly, three private facilities had phototherapy devices, but only two $(3.3 \%)$ provided the service for similar reasons.

Table 1: Comparison of the qualifications of heads of public and private PHC facilities in Jos North LGA

\begin{tabular}{lccccc}
\hline \multirow{2}{*}{ Qualification } & \multicolumn{3}{c}{ Ownership of facility } & & \\
\cline { 2 - 4 } & Public & Private & Total & $\boldsymbol{X}^{2}$ & p-value \\
& $\mathrm{N}(\%)$ & $\mathrm{N}(\%)$ & $\mathrm{N}(\%)$ & & \\
\hline CHEW & $7(23.3)$ & $9(30.0)$ & $16(26.7)$ & 20.597 & $<0.001$ \\
CHO & $4(13.3)$ & $2(6.7)$ & $6(10.0)$ & & \\
Single qualified Nurse & $0(0.0)$ & $2(6.7)$ & $2(3.3)$ & & \\
Double qualified Nurse/Midwife & $13(43.3)$ & $1(3.3)$ & $14(23.3)$ & \\
BSc. Nursing & $2(6.7)$ & $1(3.3)$ & $3(5.0)$ & & \\
MBBS & $4(13.3)$ & $13(43.3)$ & $17(28.3)$ & & \\
Others & $0(0.0)$ & $2(6.6)$ & $2(3.4)$ & & \\
Total & $30(100.0)$ & $30(100.0)$ & $60(100.0)$ & & \\
\end{tabular}

*Others - accountant and BSc public health

CHEW - Community Health Extension Worker

$\mathrm{CHO}$ - Community Health Officer 
Table 2: Comparison of socio-demographic characteristics and health care workers' training between public and private PHC facilities in Jos North LGA

\begin{tabular}{|c|c|c|c|c|}
\hline \multirow[b]{3}{*}{ Variables } & \multicolumn{3}{|c|}{ Ownership of health facility } & \multirow[b]{3}{*}{ Test statisti } \\
\hline & \multicolumn{3}{|c|}{ Number (\%) } & \\
\hline & Public $(n=67)$ & Private $(n=60)$ & Total $(n=127)$ & \\
\hline \multicolumn{5}{|l|}{ Age group (years) } \\
\hline$\leq 20$ & $0(0.0)$ & $1(1.7)$ & $1(0.8)$ & $X^{2}=20.117$ \\
\hline $21-30$ & $8(11.9)$ & $23(38.3)$ & $31(24.4)$ & $P=0.001$ \\
\hline $31-40$ & $21(31.3)$ & $21(35.0)$ & $42(33.1)$ & \\
\hline $41-50$ & $24(35.8)$ & $6(10.0)$ & $30(23.6)$ & \\
\hline $51-60$ & $14(20.9)$ & $6(10.0)$ & $20(15.7)$ & \\
\hline$>60$ & $0(0.0)$ & $3(5.0)$ & $3(2.4)$ & \\
\hline $\begin{array}{l}\text { Mean age } \pm \text { SD } \\
\quad \text { (years })\end{array}$ & $42.2 \pm 8.8$ & $36.2 \pm 11.9$ & $39.4 \pm 10.8$ & $\begin{aligned} t & =3.264 \\
P & =0.001\end{aligned}$ \\
\hline \multicolumn{5}{|l|}{ Sex } \\
\hline Female & $62(92.5)$ & $54(90.0)$ & $116(91.3)$ & $P=0.61$ \\
\hline \multicolumn{5}{|l|}{ Education } \\
\hline JCHEW & $17(25.4)$ & $21(35.0)$ & $38(29.9)$ & $X^{2}=9.290$ \\
\hline CHEW & $31(46.3)$ & $16(26.7)$ & $47(37.0)$ & $P=0.28$ \\
\hline $\mathrm{CHO}$ & $4(6.0)$ & $3(5.0)$ & $7(5.5)$ & \\
\hline $\begin{array}{l}\text { Single qualified } \\
\text { midwife }\end{array}$ & $1(1.5)$ & $3(5.0)$ & $4(3.2)$ & \\
\hline Single qualified Nurse & $5(7.5)$ & $7(11.7)$ & $12(9.5)$ & \\
\hline $\begin{array}{l}\text { Double qualified } \\
\text { Nurse/Midwife }\end{array}$ & $4(6.0)$ & $8(13.3)$ & $12(9.5)$ & \\
\hline BSc. Nursing & $2(3.0)$ & $1(1.7)$ & $3(2.4)$ & \\
\hline MBBS & $1(1.5)$ & $0(0.0)$ & $1(0.8)$ & \\
\hline Others & $2(3.0)$ & $1(50.0)$ & $3(2.4)$ & \\
\hline \multicolumn{5}{|l|}{$\begin{array}{l}\text { In-service training on } \\
\text { newborn care }\end{array}$} \\
\hline Yes & $38(56.7)$ & $31(51.7)$ & $69(54.3)$ & $X^{2}=0.325$ \\
\hline No & $29(43.3)$ & $29(48.3)$ & $58(45.7)$ & $P=0.57$ \\
\hline \multicolumn{5}{|l|}{$\begin{array}{l}\text { In-service training on } \\
\text { ENCC }\end{array}$} \\
\hline Yes & $7(10.4)$ & $15(25.0)$ & $22(17.3)$ & $X^{2}=4.680$ \\
\hline No & $60(89.6)$ & $45(75.5)$ & $105(82.7)$ & $P=0.03$ \\
\hline \multicolumn{5}{|l|}{$\begin{array}{l}\text { In-service training on } \\
\mathrm{HBB}\end{array}$} \\
\hline \multicolumn{5}{|l|}{ HBB } \\
\hline No & $55(82.1)$ & $39(65.0)$ & $94(74.0)$ & $P=0.03$ \\
\hline \multicolumn{5}{|l|}{$\begin{array}{l}\text { In -service training on } \\
\text { NRT }\end{array}$} \\
\hline Yes & $8(11.9)$ & $18(30.0)$ & $26(20.5)$ & $X^{2}=6.134$ \\
\hline No & $59(88.1)$ & $42(70.0)$ & 101(79.5) & $P=0.01$ \\
\hline
\end{tabular}




\begin{tabular}{|c|c|c|c|}
\hline \multirow[b]{2}{*}{ Deliveries } & \multicolumn{3}{|c|}{ Ownership of health facility } \\
\hline & Public $(\mathrm{n}=\mathbf{3 0})$ & $\begin{array}{c}\text { Number (\%) } \\
\text { Private }(\mathrm{n}=\mathbf{3 0})\end{array}$ & Total $(n=60)$ \\
\hline \multicolumn{4}{|l|}{$\begin{array}{l}\text { Documented records } \\
\text { of deliveries }\end{array}$} \\
\hline Yes & $20(66.7)$ & $24(80.0)$ & $44(73.3)$ \\
\hline No & $10(33.3)$ & $6(20.0)$ & $16(26.7)$ \\
\hline Range of deliveries/facility & $5-240$ & $4-229$ & \\
\hline Median (IQR) & $29(37)$ & $62(70)$ & \\
\hline Total deliveries & $896(33.0)$ & $1,820(67.0)$ & $2,716(100.0)$ \\
\hline Live births & $883(33.5)$ & $1,755(66.5)$ & $2,638(100.0)$ \\
\hline No. with records of still births & $4(13.3)$ & $6(20.0)$ & $10(16.7)$ \\
\hline Total Still births & $13(33.3)$ & $26(66.7)$ & $39(100.0)$ \\
\hline No. with records of LBW & $4(13.3)$ & $13(43.3)$ & $17(28.3)$ \\
\hline Total no. of LBW & $72(38.3)$ & $116(61.7)$ & $188(100.0)$ \\
\hline No. with records of preterms & $2(6.7)$ & $4(13.3)$ & $6(10.0)$ \\
\hline Total Preterm babies & $51(83.6)$ & $10(16.4)$ & $61(100.0)$ \\
\hline $\begin{array}{l}\text { No. with records of cong. } \\
\text { anomalies }\end{array}$ & $0(0.0)$ & $1(3.3)$ & $1(1.7)$ \\
\hline Total no. of cong. anomaly & $0(0.0)$ & $3(100.0)$ & $3(100.0)$ \\
\hline $\begin{array}{l}\text { No. with records of babies } \\
\text { referred }\end{array}$ & $1(3.3)$ & $2(6.7)$ & $3(5.0)$ \\
\hline Total no. of babies referred & $5(55.6)$ & $4(44.4)$ & $9(100.0)$ \\
\hline
\end{tabular}

$*$ LBW - low birth weight $(<2.5 \mathrm{~kg})$

IQR - Interquartile range

No. - Number

Cong. - congenital 
Table 4: Available Services and duration of services in PHC facilities in Jos North LGA

\begin{tabular}{lrrrrr}
\hline \multirow{2}{*}{ Service } & \multicolumn{3}{c}{ Ownership of facility } & \multirow{2}{*}{$\boldsymbol{X}^{2}$} & p-value \\
\cline { 2 - 4 } & Public & Private & Total & & \\
\cline { 2 - 4 } Offer 24 hours services & $\mathrm{N}(\%)$ & $\mathrm{N}(\%)$ & $\mathrm{N}(\%)$ & & \\
Yes & $14(46.7)$ & $28(93.3)$ & $42(70.0)$ & 15.556 & $<0.001$ \\
No & $16(53.3)$ & $2(6.7)$ & $18(30.0)$ & & \\
Number of hours from delivery to & & & & & \\
discharge of mothers/babies & & & & & \multirow{2}{*}{0.05} \\
Not known & $2(6.7)$ & $1(3.3)$ & $3(5.0)$ & 12.687 & \\
$\leq 1$ & $0(0.0)$ & $1(3.3)$ & $1(1.7)$ & & \\
$2-6$ & $15(50.0)$ & $5(16.7)$ & $20(33.3)$ & & \\
$7-12$ & $6(20.0)$ & $6(20.0)$ & $12(20.0)$ & & \\
$13-23$ & $1(3.3)$ & $0(0.0)$ & $1(1.7)$ & & \\
24 & $5(16.7)$ & $15(50.0)$ & $20(33.3)$ & & \\
$25-48$ & $1(3.3)$ & $2(6.7)$ & $3(5.0)$ & & \\
Immunization services & & & & & \\
Yes & $26(86.7)$ & $24(80.0)$ & $50(83.3)$ & 0.480 & 0.73 \\
No & $4(13.3)$ & $6(20.0)$ & $10(16.7)$ & \\
\hline
\end{tabular}

Table 5- Essential newborn care services provided by health care workers in PHC facilities in Jos North LGA

\begin{tabular}{lcccc}
\hline \multicolumn{5}{c}{ Ownership of health facility } \\
Variables & Pumber (\%) & & \\
\cline { 1 - 2 } $\begin{array}{l}\text { Initiate early breast feeding } \\
\text { within one hour of life }\end{array}$ & & & & \\
Yes & $61(91.0)$ & $55(91.7)$ & $116(91.3)$ & $X^{2}=0.016$ \\
No & $6(9.0)$ & $5(8.3)$ & $11(8.7)$ & $P=0.90$ \\
Counsel mother on exclusive & & & & \\
breastfeeding & & & & \\
Yes & $64(95.5)$ & $60(100.0)$ & $124(97.6)$ & $X^{2}=0.819$ \\
No & $3(4.5)$ & $0(0.0)$ & $3(2.4)$ & $P=0.37$ \\
Cord care with chlorhexidine & & & & \\
Yes & $44(65.7)$ & $42(70.0)$ & $86(67.7)$ & $X^{2}=0.271$ \\
No & $23(34.3)$ & $18(30.0)$ & $41(32.3)$ & $P=0.60$ \\
Eye prophylaxis with & & & & \\
erythromycin/tetracycline & & & & \\
Yes & $11(16.4)$ & $16(26.7)$ & $27(21.3)$ & $X^{2}=1.986$ \\
No & $56(83.6)$ & $44(73.3)$ & $100(78.7)$ & $P=0.16$ \\
$\begin{array}{l}\text { Intramuscular vitamin K1 } \\
\text { Yes }\end{array}$ & $12(17.9)$ & $14(23.3)$ & $26(20.5)$ & $X^{2}=0.572$ \\
No & $55(82.1)$ & $46(76.7)$ & $101(79.5)$ & $P=0.45$ \\
\hline
\end{tabular}




\section{Discussion}

This study found that in terms of human resource, the majority of the $\mathrm{HCWs}$ who took deliveries and performed immediate newborn care were CHEWs and JCHEWs. This was so in both public and private facilities and is similar to the situation in other parts of Nigeria. ${ }^{19-23}$ Community health workers and different categories of $\mathrm{HCWs}$ with various nomenclature also serve as birth attendants and perform immediate newborn care especially in PHCs in other LIMCs and some even in secondary facilities. ${ }^{24,25}$ However on the other hand, in High Income Countries (HICs), deliveries and immediate newborn care occurs in hospitals, birth centers and a few in planned home settings. The health care providers in these HICs are midwives, nurses, obstetricians and other physicians, depending on the level of care. ${ }^{26-28}$ Some authors have expressed concern about the pre-service curricular, entry requirements and clinical experience of CHEW and JCHEW in Nigeria compared to global standards and were doubtful if graduates of these programs have the requisite competencies needed to function adequately as skilled birth attendants in PHC facilities without direct supervision of a midwife or medical doctor. ${ }^{29}$ Since most deliveries and immediate newborn care in PHCs are conducted by CHEWs, an assessment of the CHEW pre-service program may be needed. Furthermore, in the current study, only half of the PHCs were headed by doctors or mid-wives and thus this supervisory level was lacking in some of the facilities. There is a need for employment of these levels of HCWs at the PHC level to provide supervision.

Neonatal care is linked to maternal and perinatal care, thus the birth attendant and provider of immediate newborn care plays an important role in the neonatal outcome. In 2018, the WHO joint statement revised the 2004 definition of "skilled birth attendant" to "skilled health personnel." It emphasized on education, training, certification and competencies and noted that in different countries, these competencies are held by professionals with varying occupational titles. ${ }^{30}$ The birth attendants in the PHCs in Nigeria can be regulated to meet these criteria. Implementation of the task shifting and task sharing policy may be the way forward to providing skilled health personnel at the primary level, reducing perinatal and neonatal mortality and attaining the SDG goals especially in rural areas; while encouraging the training and distribution of midwives and doctors. ${ }^{31}$ Additionally only about half of the HCWs in the our study had received any form of in-service newborn training and less than a quarter had the ENCC training. Other parts of Nigeria and other LIMCs have similarly reported low levels of newborn training amongst the HCWs involved in immediate newborn care. ${ }^{16,19,21,32}$ The role of training and re- training in any skills based health care provision cannot be over emphasized.

Although the annual deliveries per facility varied widely, the median delivery was low and the total annual deliveries at this primary level were about $30 \%$ of the total deliveries in the LGA in the same period. The Multiple Indicator Cluster Survey (MICS) in Nigeria in 2016-2017 found that the total facility delivery for the three levels in Plateau State was $43 \%$. ${ }^{33}$ Although the MICS figure was not disaggregated into LGAs, if extrapolated to Jos North LGA, our results suggest that a high percentage of the facility deliveries occur at the primary level $(30 \%$ out of $43 \%$ ), and that majority of the deliveries still occur at home. Furthermore, in our study, $67 \%$ of the deliveries in the PHCs occurred in the private facilities. This may 
be due to the fact that our study was conducted in a mainly urban area with many private facilities and likely higher social class. The relatively poor patronage of the public PHCs in our study may also not be unconnected to the fact that less than half of them offer 24 hours service, compared with over $90 \%$ of the private PHCs. It should be noted that labor can occur at any time of the day, thus restricted timing of operation will limit access. Another study in public PHCs in Enugu State in Nigeria similarly noted lack of 24 hours service in some $\mathrm{PHCs}^{34}$ Furthermore, only $17 \%$ of the public PHCs keep mother and newborn for at least 24 hours after normal delivery compared with $50 \%$ of the private PHCs. In fact, $67 \%$ of the public PHCs discharge them within six hours of delivery. This may still be linked to the fact that most of them do not offer 24 hours services. One third of newborn deaths occur within the first day of life, therefore the ENCC recommends that newborns be observed in the birth facility for at least 24 hours to ensure smooth transition. ${ }^{1}$ A number of the PHCs in our study did not fulfill this, with the risk of late detection of neonatal problems and the risk of increased neonatal morbidity and mortality.

With regards to promotive ENC services, early initiation of breast feeding was offered by $91.3 \%$ of the HCWs in our study. This is similar to $94.3 \%$ reported from Ekiti. ${ }^{35} \quad$ Similarly, about $98 \%$ of HCWs in the current study offered counseling on EBF. The availability of these services has the potential of reducing neonatal mortality as early and EBF have been associated with decreased neonatal mortality. ${ }^{36}$ Preventive ENC services that were available in the PHCs in our study included immunization services which were available in majority of the public and private PHCs. This is commendable and will reduce childhood morbidity and mortality from vaccine preventable diseases. Others included chlorhexidine cord care, where $68 \%$ of the HCWs in our study applied chlorhexidine routinely to the cord of the newborns. Although this is higher than 19\% reported from Abeokuta, it can be improved as Nigeria has adopted the use of chlorhexidine gel for all newborns to prevent cord infections and associated neonatal mortality. ${ }^{37,38}$ However, other preventive services like eye prophylaxis and vitamin $\mathrm{K} 1$ were given by less than a quarter of the HCWs. This is much lower than that reported from Ethiopia where more than half gave vit K1, and 9 out of every $10 \mathrm{HCWs}$ gave eye prophylaxis. $^{39}$ The low levels in our study may predispose the newborns to bleeding and eye infections. A surprising finding, though minimal, was the availability of incubator and phototherapy services in a private PHC. This will need to be monitored to prevent complications, as the PHC level is supposed to identify and refer sick newborns.

The limitation of this study includes the fact that some of the services could not be confirmed and were based on the report of the HCWs; nevertheless this study has implications for neonatal practice.

\section{Conclusion}

The CHEWs/JCHEWs form the majority of the human resource for immediate newborn care in Jos North LGA. There is a low level of post qualification in-service training on newborn care and particularly on the ENCC amongst the HCWs. Some preventive ENC services were lacking in most of the PHCs. In addition, many of the public facilities did not have 24 hours postdelivery services for newborns as recommended by ENCC.

Implementation of the task sharing and task shifting policy is recommended; while encouraging the training and distribution of midwives and doctors. Also in-service 
training and re-training of $\mathrm{HCWs}$ and provision of supervisory role are advocated. The public PHCs should be empowered to offer 24 hour services to improve access and ensure compliance with the ENCC recommendations. Further research to assess the knowledge and skills of the HCWs in the PHCs in Jos North LGA on newborn care are needed.

\section{Acknowledgments}

We would like to acknowledge the Plateau State Primary Health Care Board, Plateau State Ministry of Health and the heads of the PHC facilities for granting permission for this study. We thank the research assistants and $\mathrm{Mr}$ Kopse for data management.

\section{Financial support and sponsorship}

This work was supported by the Fogarty International Center (FIC); Office of the Director (OD/NIH); National Institute of Neurological Disorders and Stroke (NINDS/NIH); and the National Institute of Nursing Research (NINR/NIH) of the National Institutes of Health under Award Number D43 TW010130 - Support for Training and Mentoring in Nigerian Academics (STAMINA), University of Jos. The content is solely the responsibility of the authors and does not necessarily represent the views of the National Institutes of Health.

\section{Conflicts of interest}

There are no conflicts of interest.

\section{References}

1. United Nations Inter-agency Group for Child Mortality Estimation (UN IGME), 'Levels \& Trends in Child Mortality: Report 2020, Estimates developed by the United Nations Inter-agency Group for Child Mortality Estimation. United Nations Children's Fund, New York, 2020: 4 20.

2. World Health Organization. Every newborn progress report 2019. Geneva: World Health Organization and the United Nations Children's Fund (UNICEF), 2020: 1 - 25. License: CC BY-NC-SA 3.0 IGO.

3. World Health Organization. Fact sheet: Newborns improving survival and well-being. World Health Organization. Geneva; 2020 . Available from: https://www.who.int > Newsroom > Fact sheets (Accessed 14/4/2021).

4. United Nations Children's Fund. Every child alive: The urgent need to end newborn deaths. United Nations Children's Fund, Geneva; 2018:1 21.

5. Narayanan I, Rose M, Cordero D, Faillace S, Sanghvi T. The Components of Essential Newborn Care. Basics Support for Institutionalizing Child Survival Project (BASICS II) for the United States Agency for International Development. Arlington; 2004: 1- 7.

6. World Health Organization, Regional Office for Europe. Essential newborn care and breastfeeding: training modules. WHO Regional Office for Europe. Copenhagen; 2002: 12 - 18. https://apps.who.int/iris/handle/10665 /107481 (Accessed 21/05/2019).

7. Technical Working Group on Essential Newborn Care and World Health Organization, Maternal and Newborn Health / Safe Motherhood Unit. Essential newborn care: Report of a technical working group (Trieste, 25-29 April 1994) . World Health Organization. Geneva; 1996: 4 - 13. https://apps.who.int/iris/handle/10665 /63076 (Accessed 21/05/2019).

8. Kumar P, Khan AM. Human resource management in Primary Health Care system. Health Popul Perspect 
Issues. 2013; 36 (1 \& 2): 66-76.

9. Iganus R, Hill Z, Manzi F, et al. Roles and responsibilities in newborn care in four African sites. Trop Med Int Health. 2015; 20 (10):1258 - 1264. doi: $10.1111 /$ tmi. 12550

10. Lambo E. Basic Health Services Programme The Nigerian experience. Vikafpa. 1982;7(2):119-28. https://doi.org/10.1177/025609091982 $\underline{0205}$.

11. Plateau State. Available from: https://www.plateaustate.gov.ng/page/ jos-north (accessed 19/2/2018).

12. National Poulation Commission. Vital registration statistics. National Poulation Commission, Plateau State.

13. Federal ministry of health. Federal republic of Nigeria revised National Health Policy. Federal Ministry of Health, Abuja; 2016: 8-48.

14. Plateau State Ministry of Health. Statistics, Health Facilities. 2018 (unpublished administrative data)

15. Araoye MO. Subject selection. In: Araoye MO. Research methodology with statistics for health and social sciences. Ilorin; Nathadex; 2004: 115 $-121$.

16. Bintabara D, Ernest A, Mpondo B. Health facility service availability and readiness to provide basic emergency obstetric and newborn care in a lowresource setting: evidence from a Tanzania National Survey. BMJ Open 2019 ; 9 : e 020608 . doi:10.1136/bmjopen-2017-020608

17. American Academy of Pediatrics, World Health Organization. Essential care for every baby, provider guide. American Academy of Pediatrics. 2014: 3-64.

18. Malhotra $1 \mathrm{~S}, \mathrm{Z}$ odpey SP, Vidyasagaran AL, et al. Assessment of Essential Newborn Care Services in Secondary-level Facilities from Two Districts of India. J Health Popul Nutr 2014;32(1):130-141

19. Sarki AM. Neonatal resuscitation training and equipment in private health institutions in Kano metropolis. Niger J Basic Clin Sci 2017; 14:117-20

20. Igboanusi CJ, Sabitu K, Nmadu AG, Joshua IA, Gobir AA. A comparative study on the availability of postnatal care services in primary health-care facilities in urban and rural settlements in Kaduna State, Nigeria. Niger J Exp Clin Biosci 2020;8:44-51

21. Okusanya TF, Chinweuba AU, Nweke CI, Esievo JN. Newborn resuscitation resources in selected rural and urban primary healthcare centres in Enugu State, Nigeria: A comparative analysis. Asian Journal of Pregnancy and Childbirth. 2020; 3(3): 31-40.

22. Nkwo PO. Poor Availability of Skilled Birth Attendants in Nigeria: A Case Study of Enugu State Primary Health Care System. Ann Med Health Sci Res.2015; 5(1): 20-25.

23. Alenoghena I.O, Isah E.C, Isara A.R. Availability and Type of Human Resource for Health in Public Primary Health Care Facilities in Selected Communities, Edo State. Journal of Community Medicine and Primary Health Care. 2016; 28(2):1118.

24. Chauhan M, Sharma J, Negandhi P, Reddy S, Sethy G, Neogi SB. Assessment of newborn care corners in selected public health facilities in Bihar. Indian J Public Health 2016; 60:341-346.

25. Hobbs AJ, Moller A-B, Kachikis A, Carvajal-Aguirre L, Say L, Chou D. Scoping review to identify and map 
the health personnel considered skilled birth attendants in low-andmiddle income countries from 2000-2015. PLoS ONE. 2019; 14(2): $\mathrm{e} 0211576$.

26. Shaw D, Guise J, Shah N, et al. Drivers of maternity care in highincome countries: can health systems support woman-centred care? The $\mathrm{L}$ a n c e t. 2016 . S 0140 . $6736\left(\begin{array}{llllllll}1 & 6\end{array}\right) 31527-6$. http://dx.doi.org/10.1016/ S01406736(16)31527-6 (Acessesd August $\left.8^{\text {th }} 2021\right)$.

27. Stoll KH, Downe S, Edmonds J, et al. A Survey of University Students' Preferences for Midwifery Care and Community Birth Options in 8 HighIncome Countries. J Midwifery Womens Health 2020; 65:131-141.

28. National Academies of Sciences, Engineering, and Medicine. Birth Settings in America: Outcomes, Quality, Access, and Choice. Consensus Study Report. Washington, DC: The National Academies $\begin{array}{llllllllll}\mathrm{P} & \mathrm{r} & \mathrm{e} & \mathrm{s} & \mathrm{s} & \text {. } & 2 & 0 & 2 & 0\end{array}$. https://doi.org/10.17226/25636.

29. Adegoke AA, Mani S, Abubakar A Broek ND. Capacity building of skilled birth attendants: A review of pre-service education curricula. Midwifery. 2013;29(7): e64-e72

30. World Health Organization. Definition of skilled health personnel providing care during childbirth: the 2018 joint statement by WHO, UNFPA, UNICEF, ICM, ICN, FIGO and IPA. World Health Organization, Geneva. 2018

31. Federal Ministry of Health. Taskshifting and task-sharing policy for essential health care services in Nigeria. Federal Ministry of Health, Abuja;2014: 8-51.
32. Bolan N, Cowgill KD, Walker K, et al. Human Resources for HealthRelated Challenges to Ensuring Quality Newborn Care in Low- and Middle-Income Countries: A Scoping Review. Global Health: Science and Practice. 2021; 9(1): 160-176.

33. National Bureau of Statistics (NBS) and United Nations Children's Fund. (UNICEF). Multiple Indicator Cluster Survey 2016-17, Survey Findings Report. Abuja; 2018: 1-538.

34. Ekenna A, Itanyi IU, Nwokoro U, Hirschhorn LR, Uzochukwu B. How ready is the system to deliver primary healthcare? Results of a primary health facility assessment in Enugu State, Nigeria. Health Policy and Planning.2020; 35: i97-i106. doi: 10.1093/heapol/czaa108

35. Esan DT, Adedeji OA, Bello CB, Omolafe MC. Knowledge and practices of immediate newborn care among midwives in selected health care facilities in Ekiti State, Nigeria. Pan Afr Med J. 2020; 37(263). doi: 10.11604/pamj.2020.37.263.24628

36. Edmond KM, Zandoh C, Quigley MA, Amenga-etego S, Owusu-agyei S, Kirkwood BR. Delayed Breastfeeding Initiation Increases Risk of Neonatal Mortality. Pediatrics. 2006;117(3):e380-6.

37. Ikperite U, Ope-Babadele OO, Ojo EA. Awareness and use of chlorhexidine gel in prevention of neonatal sepsis among nurses and midwives in selected health facilities in Abeokuta, Nigeria. Saudi J Nurs Hlth Care. 2020; 3(2): 28-31.

38. Federal Ministry of Health. National strategy for scale-up of chlorhexidine in Nigeria. Federal Ministry of Health, Abuja; 2016:1-63.

39. Negussie BB, Hailu FB, Megenta 
Toma BO, ${ }^{l}$ Ofakunrin AOD, ${ }^{l}$ Diala UM, ${ }^{l}$ Kanhu ${ }^{2}{ }^{2}$ Baba $F^{3}$ Shwe DD. ${ }^{l}$

AD. Knowledge and Practice of Essential Newborn Care and Associated Factors among Nurses and Midwives Working at Health Centers in Jimma Zone, Ethiopia, 2016. J Nurs Care.2017;7(1):1-10. 